\title{
EL COSTE DE LOS DERECHOS FUNDAMENTALES. UN COMENTARIO DE LA STC 49/1999, DE 5 DE ABRIL
}

\author{
BLANCA RODRÍGUEZ RUIZ \\ Universidad de Sevilla
}

\section{INTRODUCCIÓN}

La protección de todo derecho fundamental tiene un coste. Y lo tiene no sólo en los términos estrictamente económicos recientemente analizados por Stephen Holmes y Cass Sunstein ${ }^{1}$, en el sentido, esto es, de que la realización efectiva de cada derecho requiere un mínimo de inversión económica por parte del Estado que corresponde a todos sufragar mediante el pago de impuestos. Por encima de esta circunstancia, proteger un derecho fundamental implica, necesaria y conceptualmente, algún tipo de sacrificio social. Baste recordar su papel como instrumentos de protección del individuo frente a la voluntad de la mayoría expresada democráticamente, como límites o elementos correctores de.esa voluntad. De ahí la tensión entre democracia y constitución, entre democracia y dérechos fundamentales, que preside el debate clásico entre republicanos y liberales, en que los primeros otorgan primacía a la voluntad de la mayoría y los segundos a la protección del individuo por encima de los dictados de aquélla. Ciertamente, desde la perspectiva de un modelo de democracia participativa esta tensión se disuelve ${ }^{2}$. Los derechos fundamentales se conciben aquí como garantía individual de participación en los procesos deliberativos conducentes a la formación de opiniones y

1. The Cost of Rights. Why Liberty Depends on Taxes, W.W. Norton \& Company, New York, 1999.

2. En este sentido, y è el contexto de la teoría del discurso, Jürgen HaBERmas, "Human Rights and Popular Sovereignty: The Liberal and Republican Versions", Ratio Juris, vol. 7 (1994), págs. 1 y ss. 
toma de decisiones, a nivel político pero también en el terreno social, donde los debates sirven de fuente de inspiración y de última fuente de control de los que se desarrollan en el primero. Su función es garantizar la participación de todos en dichos procesos en condiciones de igual autonomía, por encima de los intereses y de la voluntad de la mayoría. Desde esta perspectiva, democracia y derechos fundamentales constituyen requisitos complementarios y recíprocamente dependientes al servicio de un fin común ulterior, a saber la libre e igual participación de todos en la toma de decisiones políticas. Pues ni cabe participación política libre e igual sin el reconocimiento de derechos fundamentales de libertad individual, que garanticen a su vez las condiciones de participación en deliberaciones sociales, ni existe garantía del reconocimiento y respeto de estos derechos sin la libre e igual participación de todos los individuos en procesos políticos ${ }^{3}$. Todo lo cual, sin embargo, no resta valor a la observación de que la protección de un derecho fundamental tiene un coste inmediato en estrictos términos de democracia y de protección de intereses mayoritarios. Ello se traduce en casos extremos en conflictos entre derechos fundamentales y bienes constitucionales de dimensión social, cuya solución debe orientarse a maximizar la igual autonomía participativa de los individuos.

Uno de los terrenos donde el coste social de los derechos fundamentales se deja sentir con mayor crudeza es en la prohibición de utilizar en juicio la prueba obtenida como resultado de su violación, típicamente de la violación del derecho a la intimidad o de algún otro garante de un ámbito específico de ésta, como la inviolabilidad del domicilio o el secreto de las comunicaciones. No por casualidad se trata de una cuestión especialmente controvertida en el tratamiento de los derechos afectados. Pues si bien no se pone en duda la importancia de éstos y la necesidad de protegerlos, sí suscita reticencias el que ello haya de traducirse en la práctica en la tutela de intereses ilegítimos e incluso criminales, por encima del interés social general en su persecución. En la medida en que esto es así la visión individualista liberal de la intimidad suele imponerse frente a su alternativa concepción participativa, frente a su concepción como condición de participación del individuo en procesos deliberativos.

La primera de las dos visiones recién mencionadas contempla la intimidad como una esfera de retiro y de secreto que los individuos gustan tener bajo su control para poder desarrollar en ella su personalidad al resguardo de miradas indeseadas, una esfera de "retiro informativo" (informational seclusion) ${ }^{4}$ en que los individuos rechazan toda intromisión externa y cuya protección responde a intereses puramente individuales. Más aún, desde esta perspectiva, la protección de la intimidad responde, en buena lógica liberal, a intereses que se oponen frontalmente a los de la mayoría en una sociedad democrática, la cual descansa más

3. Hauke BRUNKHORST ("Menschenrechte und Souveränität -ein Dilemma?", Vortrag, Forum für Philosophie, Frankfurt am Main, 4.12.1997) ha destacado la relación de complementariedad que dichos elementos presentan ya en la obra de autores clásicos de los siglos XVIII y XIX, especialmente de Rousseau y Kant.

4. Paul M. Schwartz, "Privacy and Participation: Personal Information and Public Sector Regulation in the United States", Iowa Law Review (1995), pág. 553, 555. 
bien en la noción de publicidad y en el sometimiento del mayor número de temas posibles a discusión pública, intereses éstos últimos que se acaban imponiendo a los primeros. La concepción participativa de la intimidad la convierte, por el contrario, en presupuesto de la libre participación del individuo en los procesos deliberativos que constituyen la base de toda sociedad democrática. Y ello en un doble sentido. En primer lugar, sólo cabe deliberación libre donde ésta ha sido libremente elegida. De ahí la necesidad de proteger la opción individual por el retiro y el secreto. En segundo lugar, una vez que se ha optado por tomar parte en una deliberación concreta, ésta sólo puede desarrollarse libremente en la medida en que todos sus participantes controlen la existencia de zonas de retiro y de secreto en que poder desarrollar su personalidad libremente, sin contar con intromisiones indeseadas. Pues la participación de quien carezca de control sobre tales zonas estará siempre condicionada por el temor de que alguna información sobre su persona se encuentre en el poder de terceros y pueda ser utilizada en su perjuicio. Se trata de la noción, no de retiro informativo, sino de "autodeterminación informativa" (informationelles Selbstbestimmung) ${ }^{5}$. Mientras la primera contempla la intimidad desde el exterior, desde el punto de vista del espacio que su protección priva al conocimiento y valoración del público, la segunda se concentra no tanto en la intimidad como en la libertad de actuación que ella confiere y en la importancia que dicha libertad tiene en términos de participación y democracia.

Pues bien, no parece casual que allí donde la protección de la intimidad se sitúa al servicio de intereses que se estiman dignos de protección la libertad que de ella se deriva se convierte en centro de atención y su protección se defiende en términos participativos. Por otro lado, donde esos intereses no parecen merecer tutela lo que pasa a ocupar el primer plano es la intimidad en sí misma como espacio privado al público en aras de intereses individuales y en última instancia antidemocráticos, lo que lleva a minimizar la importancia de su protección. Así, en Europa, donde predomina la visión participativa de la intimidad ${ }^{6}$, la necesidad de protegerla se pone a menudo en cuestión cuando parece servir este último tipo de intereses, sobre todo de intereses que en última instancia y en el caso concreto encierran un elemento de ilegalidad 7 . En Estados Unidos, donde prevalece por el contrario una visión individualista de la intimidad, la Corte Suprema ha enfatizado con todo su dimensión participativa en la medida en que la intimidad aparece al servicio de derechos de libertad que representan precisamente dicha dimensión. Así la Corte ha destacado la importancia de la intimidad donde con ella se protege la autonomía individual para tomar decisiones íntimas ${ }^{8}$. Asimismo

5. $B \operatorname{VerfGE} 65,1$ esp. 43 y ss.

6. En este terreno ha sido crucial el papel del Tribunal Constitucional Federal alemán, sobre todo el de su decisión de 1983 sobre el Censo (BVerfGE 65, 1), donde la intimidad fue definida como un aspecto del derecho a la autodeterminación reconocido en el artículo 2.I de la Ley Fundamental, en concreto como derecho a la autodeterminación informativa.

7 Sobre este punto Spiros SimITIS, "Daten- oder Tatenschutz - ein Streit ohne Ende?" NJW 1997, pág. 1902.

8. Griswold v. Connecticut, 381 U.S. 479 (1965), en que la Corte declaró la inconstitucionalidad de una ley de Connecticut que prohibía el uso de contraceptivos incluso por parejas casadas, alegando 
ha puesto en conexión la tutela de la intimidad con la de las libertades reconocidas en la Primera Enmienda, a saber las libertades religiosa, de expresión y de petición, así como la libertad de asociación, implícitamente reconocida en la Enmienda, según la Corte Suprema, como libertad periférica de las anteriores. Lo cual significa que dichas libertades reconocen consigo el derecho a ejercerlas en secreto", que "la Primera Enmienda posee una penumbra en que la intimidad se protege frente a intromisiones gubernamentales ${ }^{10}$, y donde la importancia participativa de la intimidad pasa a ocupar el primer plano en virtud de la importancia participativa de la libertad que con ella se protege. Por otro lado, la visión individualista de la intimidad preponderante en los Estados Unidos se ha desarrollado en el contexto de la garantía de la Cuarta Enmienda frente a registros y embargos irrazonables ${ }^{11}$, una garantía cuya tutela suele reclamarse por los autores de hechos delictivos, normalmente de cara a obtener la exclusión en juicio de prueba incriminatoria obtenida con intrusión irrazonable en su intimidad. De ahí la tendencia a minimizar la importancia de la intimidad en este contexto, incluso a reducir en lo posible sus dimensiones conceptuales, para evitar precisamente que su protección desemboque en la exclusión de prueba incriminatorią relevante. De ahí también la controversia que la figura de la exclusión en sí misma suscita, y la tendencia a romper el nexo causal que la une a la protección de la intimidad. Sobre ello se habrá de volver más adelante.

De las dudas que circundan la figura de la exclusión de la prueba inconstitucional dan buena fe las más recientes decisiones de nuestro Tribunal Constitucional sobre el tema, emitidas en el contexto del derecho al secreto de las comunicaciones, especialmente las SSTC 81/1998, de 2 de abril, y 49/1999, de 5 de abril, así como el voto particular del Presidente del Tribunal, el Magistrado don Pedro Cruz Villalón, a ésta última. Pues bien, el objetivo principal de este artículo es realizar un comentario crítico de la doctrina constitucional sobre la exclusión de la prueba inconstitucionalmente obtenida, tomando como punto de referencia concreto la segunda de las sentencias arriba mencionadas. Y decía que es éste su objetivo principal porque esta sentencia incide sobre una serie de cuestiones adicionales igualmente merecedoras de comentario. Se trata, como enseguida veremos, y al igual

la violación de un derecho general a la intimidad implícitamente reconocido en la Constitución. Tal derecho se ha puesto en conexión posteriormente con la libertad en el uso de contraceptivos de las parejas no casadas (Eisenstadt v. Baird, 405 U.S. 438 (1972); Carey v. Population Services International, 431 U.S. 678 (1977)), con la libertad de abortar (Roe v. Wade, 410 U.S. 113 (1972)), o con la libertad de obtener drogas legales con prescripción facultativa (Whalen v. Roe, 429 U.S. 589 (1976)).

9. Así la libertad de asociación implica el derecho a no revelar nuestra pertenencia a asociaciones (NAACP v. Alabama, 357 U.S. 449 (1858); Gibson v. Florida Legislative Investigative Committee, 372 U.S. 539. (1963)); la libertad de expresión incluye el derecho a distribuir notas y panfletos anónimos (Talley v. California, 362 U.S. 60 (1960); McIntyre v. Obio Elections Commission, 514 U.S. 334 (1995)); véase también la reciente Buckley v. American Constitutional Law Foundation, Inc. et al., 119 S.Ct. 636 (1999), en relación con el derecho de iniciativa legislativa popular como aspecto de la libertad de expresión política.

10. Griswold v. Connecticut, 381 U.S. 479, 483 (1965).

11. Sobre este tema, Blanca Rodríguez Ruz, El secreto de las comunicaciones: tecnologia e intimidad, McGraw-Hill, Madrid, 1998, págs. 34 y ss. 
que en el caso de la exclusión de la prueba, de cuestiones cuyo alcance trasciende el ámbito del derecho al secreto de las comunicaciones, cuestiones en las que la problemática relativa a este derecho aparece simplemente como la punta de un iceberg que en última instancia concierne de forma genérica a la concepción de los derechos fundamentales. A continuación, y antes de abordar la cuestión relativa a la exclusión de la prueba inconstitucional, comenzaré comentando esos otros puntos relevantes de la STC 49/1999.

\section{LA STC 49/1999, DE 5 DE ABRIL}

Las circunstancias del caso, que se desarrollan entre finales de 1986 y los primeros meses de 1987, son resumidamente las siguientes. El Grupo de Investigación Fiscal y Antidroga de la Guardia Civil de Málaga había recibido información confidencial que apuntaba a la introducción ilegal en España de drogas tóxicas desde Marruecos. Tales confidencias le condujeron a solicitar autorización judicial para intervenir los teléfonos de quienes parecían responsables u organizadores de tales hechos. El juzgado de instrucción número 1 de Ceuta respondió a dicha solicitud con la incoación de diligencias indeterminadas en las que autorizó mediante los correspondientes autos las intervenciones requeridas, autorización cuya renovación se fue solicitando y concediendo periódicamente. A esa primera solicitud siguió otra de intervención de otra línea telefónica, autorizada mediante auto por el juzgado de instrucción número 6 de Málaga igualmente en el seno de diligencias indeterminadas, y cuya prórroga se solicitó y autorizó con posterioridad mediante providencia. La información recabada de dichas intervenciones llevó a conocer la fecha de entrega de un cargamento de hachís en las proximidades de un restaurante de Torremolinos, de modo que los agentes policiales, tras controlar los movimientos de los sospechosos, finalmente interceptaron la introducción de la droga en nuestro país, incautándola y deteniendo a quienes habían realizado la operación de desembarco. Asimismo detuvieron a quienes consideraban responsables de la operación sin haber participado físicamente en ella. Todos ellos fueron acusados y condenados como autores de un delito contra la salud pública y otro de contrabando. Los últimos lo fueron con base en la transcripción del contenido de las grabaciones de las conversaciones telefónicas intervenidas y en la declaración testifical de los agentes policiales que las practicaron. La condena de los primeros se apoyó, además, en su captura como partícipes en el desembarco de la droga y en la declaración testifical de los agentes que realizaron el seguimiento de dicha operación. Las condenas fueron confirmadas en casación por el Tribunal Supremo.

Los condenados presentaron respectivos recursos de amparo ante el Tribunal Constitucional, avocados al Pleno, los cuales se basan esencialmente en una serie de alegaciones comunes que se refieren a la violación del derecho al secreto de las comunicaciones (art. 18.3 CE), del derecho a un proceso con todas las garantías (art. 24.2) y, en conexión con éste último, a la presunción de inocencia. En primer lugar, la autorización judicial de intervención de comunicaciones tuvo lugar 
en el contexto de las llamadas diligencias indeterminadas, como medida exploratoria previa a la apertura de un proceso, en contradicción pues con los dictados del artículo 579 de la Ley de Enjuiciamiento Criminal (LECrim). El cual requiere que la intervención de comunicaciones sea ordenada en el seno de un proceso penal y contra la parte pasiva en él, es decir, contra la persona del acusado ${ }^{12}$. Se alega en segundo lugar la falta de motivación de los autos judiciales de intervención de conversaciones telefónicas y de sus sucesivas prórrogas y, en tercer lugar, que no se realizó control judicial alguno de las intervenciones practicadas, siendo las prórrogas ordenadas sin previa inspección judicial de los resultados de las intervenciones anteriores. En cuarto lugar, no se entregaron al juez instructor las grabaciones originales, sino meras transcripciones resumidas y extractadas por la autoridad gubernativa; la traducción del árabe y del italiano al castellano de parte de dichas conversaciones se produjo, además, sin intervención de traductor debidamente habilitado. Dichas grabaciones originales, por último, no fueron introducidas en el juicio oral, lo que imposibilitó su contradicción. Algún recurrente alega también la falta de cobertura legal suficiente de las intervenciones telefónicas que se discuten, con violación por tanto del artículo 18.3 en conexión con el 53.1 de la Constitución. Pues el artículo 579 de la LECrim vigente al tiempo de ordenarse tales intervenciones sólo contenía el actual apartado primero, en el que exclusivamente se autoriza la intervención de comunicaciones escritas. Sólo en virtud de su reforma por la L.O. 4/1988, de 25 de mayo, pasó este artículo a autorizar también la de conversaciones telefónicas.

Es esta última cuestión la primera cuya solución aborda el Tribunal Constitucional. Su solución es, en efecto, preliminar a la de las demás. Pues si toda orden judicial de intervención de comunicaciones debe tener respaldo legal en virtud del artículo 53.1 de la Constitución, en concreto el respaldo de una ley orgánica (artículo $81.1 \mathrm{CE}$ ), las que se realizaron en el presente caso han de considerarse ya por este simple motivo inconstitucionales. Lo primero que ha de decidirse es por tanto el papel que el artículo 53.1 juega en relación con las restricciones de derechos fundamentales, en general, y del derecho al secreto de las comunicaciones, en concreto. Recientemente he tenido ocasión de analizar dicho papel en el contexto, precisamente, del derecho al secreto de las comunicaciones $^{13}$. El punto de partida de dicho análisis era la concepción de nuestros derechos fundamentales, abiertamente defendida desde fecha temprana por nuestro Tribunal Constitucional ${ }^{14}$, como derechos ilimitables por el legislador, como derechos cuyo ámbito de protección se encuentra definido exclusivamente por los límites que se desprenden del reconocimiento de otros derechos o principios de rango constitucional. Consecuencia de esta concepción es que el legislador no

12. Sobre ello, y sobre la confusión que en este punto suscita el tenor literal del artículo 579, véase Blanca RoDríguez Rurz, El secreto de las comunicaciones..., cit. pág. 91.

13. "El caso Valenzuela Contreras y nuestro sistema de derechos fundamentales", REDC núm. 56 (1999), págs. 223 y ss.

14. STC $11 / 1981$, FJ 7.; cifr. Manuel MEDINA GUIRri:RO, La vinculación negativa del legislador a los derechos fundamentales, McGraw-Hill, 1996, pág. 72. 
puede imponer restricciones llamémosles externas al ejercicio de los derechos fundamentales, restricciones que no se desprenden de la propia Constitución. Posibles son sólo, por el contrario, las contenidas en lo que la doctrina alemana ha dado en llamar "límites inmanentes" de los derechos fundamentales, límites implícitos en el texto constitucional y que al legislador corresponde simplemente concretar $^{15}$. Concreción que suele articularse como el resultado de una ponderación de los distintos principios constitucionales en juego ${ }^{16}$. Es más, ese carácter inmanente de los límites de los derechos fundamentales los convierte en concretables no sólo por el legislador, sino por cualquier operador jurídico. En nuestro marco constitucional, y para ser más precisos, el artículo 53.1 otorga en exclusiva al legislador la labor de concretar el ámbito de protección de estos derechos en el contexto de la regulación de las condiciones de su ejercicio. Su concreción en cada supuesto específico de aplicación de los derechos fundamentales queda en principio abierta a todo operador jurídico, eventualmente sometida al control del poder judicial y en última instancia del Tribunal Constitucional ${ }^{17}$. Todos esos operadores deberán, claro está, respetar la regulación legislativa del derecho de haberse ésta producido. Pero de no haber sido así, la Constitución servirá, como norma jurídica directamente aplicable, de inmediato punto de referencia en la protección o restricción de los derechos fundamentales en casos concretos. Hay por lo demás supuestos en que la Constitución exige que la restricción en casos específicos del ejercicio de algún derecho determinado sea llevada a cabo exclusivamente por el poder judicial. Entre ellos se encuentra precisamente el derecho al secreto de las comunicaciones reconocido en el artículo 18.3.

Sobre la base de la concepción recién descrita de los derechos fundamentales, nuestro Tribunal Constitucional ha venido reconociendo, de forma más o menos explícita, pero en todo caso como una obviedad, la constitucionalidad de las órdenes judiciales de restricción del derecho al secreto de las comunicaciones dictadas sin cobertura legal, en ausencia pues de regulación legislativa de las condiciones generales del ejercicio de dicho derecho ${ }^{18}$. Todo ello, por supuesto, siempre que dichas órdenes reuniesen una serie de requisitos materiales, siempre que pudieran considerarse en sí mismas conformes a la Constitución. Ello supone una superación de la visión liberal tradicional de los derechos fundamentales, que los concibe como derechos naturales cuya positivación los somete en última instancia a los dictados del legislador. Tal visión de los derechos se identifica, en puridad, con su función como principios puramente programáticos predominante durante el constitucionalismo decimonónico, y aun ya en el contexto del constitucionalismo normativo imperante desde la segunda postguerra los sigue concibiendo como

15. Sobre la noción de concretar, véase más abajo la nota 40 y su texto correspondiente.

16. La cual, con todo, debería articularse más bien como el resultado de identificar la norma cuya aplicación al caso mejor respeta la coherencia del ordenamiento jurídico: véase la nota 42 y su texto correspondiente.

17. La relación entre la regulación y la aplicación de los derechos fundamentales será aclarada en el apartado 4 .

18. SSTC 22/1984, de 17 de febrero, FJ $3 .^{\circ} ; 85 / 1994$, de 14 de marzo, FJ $3 .^{\circ}$ 
derechos esencialmente sujetos a restricciones legales. En ella se encuadran los que la doctrina alemana conoce como derechos sujetos a reserva de ley (Gesetzvorbehalt), por oposición a los que no lo están (gesetzvorbehaltlose Grundrechte), a los que están simplemente sujetos a límites inmanentes. El ámbito de protección de los primeros resulta de la imposición de límites a la capacidad limitativa del legislador, límites de los que en última instancia depende la vigencia efectiva de estos derechos. De ahí la figura del contenido esencial, y de ahí sobre todo el principio de proporcionalidad, según el cual los límites legislativos de los derechos fundamentales deben ser adecuados, indispensables y proporcionales a la consecución de un fin que basta que sea legítimo, que no debe pues necesariamente tener rango constitucional, un fin cuya importancia relativa no se pondera con la del derecho que en aras de su consecución se pretende limitar ${ }^{19}$.

Esta concepción liberal tradicional de los derechos fundamentales como naturales, aparentemente superada por nuestra Constitución, subyace aún al Convenio Europeo de Derechos Humanos (CEDH), donde todos los derechos están sometidos a reserva de ley y su ámbito de protección se define mediante la imposición de límites al legislador. Y son precisamente las diferencias que la separan de nuestra visión de los derechos fundamentales las que condujeron a la reciente condena de España por el Tribunal Europeo de Derechos Humanos (TEDH) en el caso Valenzuela Contreras c. España ${ }^{20}$. El motivo de la condena fue la violación por los tribunales españoles del derecho al secreto de las comunicaciones reconocido en el artículo 8 del Convenio. El apartado 2 de este artículo requiere que toda injerencia pública en el ejercicio del derecho esté prevista por la ley, entendida como una norma con fuerza de ley, la cual puede con todo ser complementada por otras de rango inferior ${ }^{21} \mathrm{y}$ por la jurisprudencia de jueces y tribunales ${ }^{22}$, y que debe reunir una serie de requisitos materiales. En concreto, debe tratarse de una norma accesible, sobre cuya base las injerencias permitidas sean previsibles por los titulares del derecho. Pues «una norma no puede considerarse 'ley' a menos que esté formulada con precisión suficiente para permitir al ciudadano regular su conducta: éste debe ser capaz ... de prever, en un grado razonable dadas las circunstancias, las consecuencias que puedan derivarse de una determinada acción ${ }^{23}$. Pues bien, las órdenes judiciales de intervención telefónicas denunciadas en el caso Valenzuela se habían producido, al igual que las recurridas en la STC 49/1999, antes de que la reforma de la LECrim por la L.O. 4/1988 hubiera introducido la autorización de dichas órdenes, antes incluso del desarrollo por el Tribunal Constitucional de su doctrina sobre la razonabilidad de las mismas, siendo pues el artículo 18.3 de la Constitución su único soporte normativo. Y aunque este artícu-

19. En "El caso Valenzuela Contreras ...", cit. criticaba la relativamente reciente asunción por nuestro Tribunal Constitucional de este juicio de proporcionalidad. En cuanto al contenido esencial de los derechos fundamentales, me remito también a una crítica anterior y en términos genéricos de esta figura, esta vez en El secreto de las comunicaciones...., cit. págs. 107 y ss.

20. Sentencia de 30 de julio de 1998, Reports of Judgments and Decisions 1998-V.

21. Silver y otros c. R.U., sentencia de 25 de marzo de 1983, Serie A, vol. 61, Par. 88, pág. 33.

22. Kruslin c. Francia, sentencia de 24 de abril de 1990, Serie A, vol. 176, Par. 29, págs. 21- 
lo ofrece base legal formal a las órdenes judiciales de intervención telefónica y es además, qué duda cabe, perfectamente accesible, no satisface por sí solo el requisito material de previsibilidad de la ley. De ahí la violación del artículo 8.2 del CEDH.

Pues bien, en la sentencia que aquí se comenta el Tribunal Constitucional se encuentra antę el dilema de, o bien acatar la doctrina sentada por el TEDH, de asumirla a pesar de su crasa oposición con nuestra concepción de los derechos fundamentales, o bien seguir los dictados de dicha concepción por encima de la sentencia del TEDH, ignorando pues la obligación constitucional de interpretar los derechos fundamentales de conformidad con los tratados internacionales sobre la materia ratificados por España (artículo 10.2 CE). Obviamente insatisfecho con una y otra solución, el Tribunal opta por una vía de compromiso. Nominalmente alega respetar el razonamiento y la conclusión del TEDH en el caso Valenzuela, integrando incluso el requisito de la previsibilidad de las intervenciones telefónicas legalmente autorizadas en nuestro derecho constitucional interno (FJ 4..$^{\circ}$ ). A renglón seguido, sin embargo, matiza que hay ocasiones en que una orden judicial de intervención telefónica dictada sin respaldo legal puede con todo considerarse conforme a la Constitución. Esto es así si los órganos judiciales actuaron en el marco de la investigación de una infracción grave, en la que de modo patente fuera necesaria, adecuada y proporcionada la intervención telefónica, si ésta fue ordenada respecto de personas presuntamente implicadas en el mismo y si se respetaron las exigencias constitucionales del principio de proporcionalidad, proporcionalidad entendida ahora en términos de razonabilidad ${ }^{24}\left(\mathrm{FJ} 5^{\circ}\right.$ ). En definitiva, aunque el Tribunal declara seguir los dictados del TEDH, parece resistirse en última instancia a abandonar su visión del derecho al secreto de las comunicaciones. La contradicción implícita en este razonamiento, debidamente destacada en el voto particular de Cruz Villalón, sólo tiene sentido si se la contempla con el dilema arriba apuntado como telón de fondo. Un dilema que cuanto menos pone en evidencia la superficialidad en este terreno de lo que en tono optimista se ha calificado de "cultura jurídica europea" ${ }^{25}$. Y no es que el Tribunal quiera arriesgarse a una nueva condena por el TEDH. No parece aventurado suponer que su tributo a la concepción de los derechos fundamentales en nuestro derecho interno es una concesión que el Tribunal se permite a sabiendas de que el análisis sustantivo del caso conducirá al otorgamiento del amparo a los recurrentes. Ni parece excesivo especular que precisamente el afán por evitar condenas futuras condiciona el tono general de cautela que preside el tratamiento del derecho al secreto de las comunicaciones en la sentencia, un tono cuyas manifestaciones concretas constituyen, en líneas generales, el legado positivo del caso Valenzuela.

El segundo motivo de inconstitucionalidad que el Tribunal Constitucional resuelve es el relativo al contexto en que se dictan los autos judiciales de autori-

23. Silver y otros C. R.U., opinión de la Comisión de 11 de octubre de 1980, Serie B, vol. 51, Par. 282, pág. 74 .

24. Véase la nota 27.

25. Peter HÄBERLE, Europäiscbe Recbtskultur, Nomos Verlaggesellschaft, Baden-Baden, 1994. 
zación de las intervenciones telefónicas, las llamadas diligencias indeterminadas. El problema surge de que, tanto antes como después de su reforma, el artículo 579 LECrim sólo autoriza la intervención de comunicaciones ordenada en el seno de un proceso penal contra la persona del acusado, no como parte de las diligencias indeterminadas, como medida de exploración previa a la apertura de un proceso. El Tribunal se enfrenta aquí a una cuestión de fondo que podríamos formular en los siguientes términos: ¿constituye la regulación del artículo 579 LECrim la única concreción posible del ámbito de protección del derecho fundamental al secreto de las comunicaciones? En línea de principio, parece claro que la regulación legal del ejercicio de un derecho no es necesariamente su única fuente de concreción, que el ámbito de protección de un derecho no tiene porqué identificarse con el que es objeto de regulación legal. Ello es así primariamente en relación con el Tribunal Constitucional. El cual, como intérprete supremo de la Constitución, asumirá la concreción legal del ámbito de protección de un derecho en la medida en que sea conforme con aquélla, pero la corregirá e incluso la completará en la medida en que la Constitución requiera que sea corregida o completada. La interpretación arriba asumida del papel del artículo 53.1 de las Constitución apunta a la misma solución respecto de los demás operadores jurídicos. Los cuales, como hemos visto, pueden en la solución de casos específicos concretar el ámbito de protección del derecho más allá del ámbito previsto por las leyes que regulan su ejercicio. Cabe con todo la salvedad de que dichas leyes tengan vocación de exhaustividad, o bien excluyan ciertas instancias de concreción del derecho, supuestos uno y otro cuya confirmación depende en última instancia del Tribunal Constitucional.

El artículo 5.79 LECrim parece tener la apuntada vocación de exhaustividad. En sus tres primeros apartados se autoriza al juez a acordar por resolución motivada la detención de la correspondencia y la intervención de las comunicaciones telefónicas del acusado en un proceso criminal si hubiere indicios de que por estos medios se pueden descubrir o comprobar hechos o circunstancias importantes de la causa ${ }^{26}$; y, parece deducirse, en ningún otro caso. Corresponde ahora al Tribunal Constitucional juzgar si dicha vocación está constitucionalmente justificada. Y, efectivamente, en el FJ 6..$^{\circ}$ de la STC 49/1999, el Tribunal confirma que la autorización de intervención de comunicaciones debe ser dictada por un juez en el marco de un proceso, con participación pues del Ministerio Fiscal. La intervención de comunicaciones, razona el Tribunal, se lleva necesariamente a cabo sin conocimiento del interesado, que no puede por tanto controlar ni en su caso recurrir la restricción de su derecho al secreto de dichas comunicaciones. De ahí la importancia del control ejercido por el Ministerio Fiscal. Ahora bien, prosigue el Tribunal, tal control se produce en última instancia donde las diligencias indeterminadas se unen sin solución de continuidad a un proceso judicial de averiguación del delito investigado, lo que en

26. Sobre la confusa redacción de estos tres apartados, y para una defensa de la interpretación conjunta de los mismos que aquí se ofrece, consúltese Blanca Rodríguez Ruiz, El secreto de las comunicaciones..., cit. págs. 89 y ss. 
tales supuestos salva la constitucionalidad de las intervenciones ordenadas en el contexto de las primeras. De este modo lo que está ofreciendo el Tribunal es una justificación de la constitucionalidad de la intervención pre-procesal de comunicaciones en función de su resultado: allí donde éste sea positivo y conduzca a la apertura de un proceso su constitucionalidad está salvada, mientras que no lo estará donde su resultado sea negativo. Una justificación que no es en absoluto convincente. Más bien la constitucionalidad de las mencionadas intervenciones debe analizarse en sí misma y por sus propios méritos, con independencia de los resultados que con ellas se obtengan en un caso determinado. El tono con que resuelve este punto parece indicar que, de haber contemplado la cuestión en tales términos abstractos, el Tribunal se habría inclinado, si no por descartar la conformidad constitucional de las intervenciones controvertidas, sí al menos por matizarla, previsiblemente sobre la base de criterios que, como veremos, él mismo introduce al conocer de su constitucionalidad material. En otras palabras, no parece aventurado suponer que un análisis abstracto de la cuestión hubiera llevado al Tribunal a hacer depender la constitucionalidad genérica de las intervenciones pre-procesales de criterios materiales, de los mismos criterios en los que se apoya al analizar su constitucionalidad material en este caso concreto.

No hay que olvidar, con todo, que en el momento de producirse las órdenes judiciales de intervención telefónica controvertidas la regulación de la LECrim sólo afectaba a la intervención de comunicaciones escritas y no era por tanto de aplicación al caso. Imponer entonces al juez la prohibición de ordenar intervenciones telefónicas en el marco de diligencias indeterminadas equivale a asumir que dicha prohibición constituye una concreción necesaria, en el sentido de constitucionalmente obligada, del ámbito de protección del derecho al secreto de las comunicaciones, con independencia de su regulación legal. Ello explica el interés del Tribunal Constitucional por determinar la razón de ser última de la restricción de la intervención de comunicaciones a un proceso penal y a la persona del acusado, y por analizar si la misma había sido respetada en el caso concreto, habida cuenta de todas sus circunstancias. La tambaleante solución a que llega el Tribunal podría haber estado condicionada por esta situación; la cual no puede, con todo, servir para justificarla.

Una vez resueltas estas dos cuestiones de tipo preliminar el Tribunal Constitucional pasa a conocer del fondo del asunto, es decir de la constitucionalidad, en el sentido de la razonabilidad o proporcionalidad ${ }^{27}$, de las injerencias en el derecho al secreto de las comunicaciones en sí mismas consideradas, con independencia de

27. Nótese que desde fecha relativamente reciente, al realizar este tipo de análisis el Tribunal no se concentra ya, como tradicionalmente hacía, en determinar la existencia de un interés de rango constitucional que justifique la restricción del derecho fundamental en juego, y en ponderar la relevancia relativa en términos constitucionales de la protección de uno y de otro en el caso concreto. Es éste, en efecto, el análisis que corresponde a derechos fundamentales no limitables por el legislador, sino sometidos exclusivamente a límites constitucionales inmanentes. Pues bien, en un giro jurisprudencial que ya he tenido ocasión de criticar (véase la nota 19), el Tribunal ha sumado a este análisis el triple test de proporcionalidad con que en derecho alemán se determina la constitucionalidad de las restricciones de los derechos fundamentales que el legislador sí está autorizado a limitar. 
su marco normativo y de su contexto procesal. Este último, con todo, va a seguir condicionando los términos del análisis. Pues de haberse producido las intervenciones telefónicas en el marco de un proceso y contra la persona del acusado, su razonabilidad hubiera estado ya en buena medida justificada, en mayor medida al menos que en el caso presente, en que debe demostrarse ante todo la relación entre la intervención telefónica y la investigación de un delito, entre la presunta autoría de dicho delito y los usuarios de los teléfonos intervenidos. El Tribunal Constitucional se enfrenta pues a la razonabilidad o proporcionalidad de las órdenes judiciales desde esta perspectiva.

Lo primero que exige es que dicha relación haya sido asumida en la motivación de las órdenes judiciales. Desde su más temprana jurisprudencia, el Tribunal Constitucional ha subrayado que la motivación es, en efecto, requisito de constitucionalidad imprescindible de toda limitación de un derecho fundamental, orientado a que "los destinatarios conozcan las razones por las cuales su derecho se sacrificó y los intereses a los que se sacrificó. De este modo, la motivación no es sólo una elemental cortesía, sino un riguroso requisito del acto de sacrificio de los derechos ${ }^{28}$. Ello significa, por un lado, que las órdenes judiciales de restricción de un derecho deben estar motivadas, no ya formalmente, sino también desde el punto de vista material. Deben pues expresar las razones por las que se limita un derecho y los intereses a los que se sacrifica su disfrute, argumentando además que las unas y los otros justifican en el caso concreto la limitación impuesta a ese derecho, que ésta es el resultado de una adecuada ponderación de los intereses en conflicto ${ }^{29}$. Significa igualmente, y por otro lado, que las órdenes judiciales de restricción de un derecho no sólo deben estar materialmente justificadas sino que, a nivel formal, deben expresar suficientemente las razones por las que lo están, hasta el punto de que la falta de expresión de dichas razones se equipara a su inexistencia, y que al Tribunal Constitucional tan sólo le corresponde supervisar la expresión de una fundamentación que permita reconocer la concurrencia de todos los extremos que justifican la restricción del derecho. Esta ya temprana doctrina fue expresamente asumida en el contexto del derecho al secreto de las comunicaciones con la STC 85/1994, de 14 de marzo. Pues bien, en el caso presente, las órdenes judiciales debían motivar suficientemente que la injerencia en el derecho al secreto de las comunicaciones afectaba a quienes fundadamente podían ser provisionalmente tenidos como responsables del delito que estaba siendo investigado, o a quienes estaban relacionados con ellos. Y debían hacerlo, no sobre la base de meras creencias, hipótesis o conjeturas de que dicho delito pudiera estarse cometiendo o llegar a cometerse, sino sobre la base de sospechas fundadas en datos objetivos. Por tales entiende el Tribunal datos accesibles a terceros, y por tanto susceptibles de control, y que proporcionen además una base real de la que poder inferir que las líneas cuya intervención se ordenaba estaban siendo utilizadas por

28. STC 85/1994, de 14 de marzo, FJ $3 .^{\circ}$, citando la STC $26 / 1981$, de 17 de julio.

29. STC $57 / 1994$, de 28 de febrero, FJ $6 .^{\circ}$ 
personas sospechosas de la comisión del delito investigado, o por quienes con ellas se relacionaban (FJ $8^{\circ}$ ). De este modo, y con la introducción de estos criterios de objetividad, se evita que la intervención de comunicaciones pueda servir como medida de investigación meramente prospectiva incluso en el contexto de las diligencias indeterminadas. Se trata pues de someter las órdenes judiciales de intervención de comunicaciones dictadas en este contexto a baremos de constitucionalidad comparables a los que rigen en el contexto de un proceso penal, matizando así los efectos del reconocimiento de su constitucionalidad. Pues bien, la aplicación de dichos baremos conduce a la declaración de inconstitucionalidad de las injerencias en el derecho al secreto de las comunicaciones. Y es que las solicitudes policiales de órdenes judiciales de intervenciones telefónicas se habían basado en meras sospechas y conjeturas en relación con las cuales no se proporciona fundamento objetivo claro, sospechas que el órgano judicial autorizante se limita a asumir en su motivación sin requerir mayor esclarecimiento de los hechos. Lo cual no quiere decir que dicho fundamento materialmente no existiera. Simplemente no se le da suficiente expresión ni en la solicitud policial de la medida de intervención ni en la resolución judicial que la autoriza, lo que a efectos jurídicos sí lo convierte, efectivamente, en inexistente (FFJ $9 .^{\circ}-100^{\circ}$ ).

$\mathrm{Y}$ es interesante comparar la decidida posición que el Tribunal Constitucional sostiene en este punto, su insistencia en la objetividad de los motivos expresados por el juez para justificar la intervención como un requisito de razonabilidad de ésta, posición que debe por lo demás compartirse, con la que adoptara en su STC 81/1998, de 2 de abril. En ella el Tribunal había mostrado un alto grado de respeto a las apreciaciones subjetivas de la policía, a las que concede una relevancia superior a la que su nivel de objetividad parecería merecer, mostrándose abierto a aceptar su asunción por el órgano judicial que autorizó la intervención de comunicaciones como motivos suficientemente justificativos de ésta (FJ $50^{\circ}$ ). La STC 49/1999 reconsidera tales cuestiones e introduce en el giro de un año un ostensible cambio de posición respecto a ellas, tanto en lo que concierne a la relación entre la motivación de la orden judicial y los motivos aducidos por la policía al solicitarla, como a la objetividad de los argumentos utilizados por unas y otros. Se trata, en definitiva, de un vuelco jurisprudencial, cuya rápida introducción es testimonio del clima de cautela que la condena de España en el caso Valenzuela parece haber introducido en el tratamiento del derecho al secreto de las comunicaciones, y que en todo caso retoma el tradicional tono protector de la jurisprudencia del Tribunal Constitucional sobre la motivación de las órdenes de intervención de comunicaciones, un tono interrumpido por la STC 81/1998.

De este modo, y aunque las órdenes judiciales examinadas estaban formalmente motivadas, su motivación no reunía los requisitos de objetividad que el Tribunal Constitucional considera ahora indispensables para que lo estuvieran también materialmente. Lo mismo cabe decir de sus prórrogas. De las dictadas por el juzgado de instrucción de Ceuta, sólo la solicitud de la primera se razona sobre la base de los resultados obtenidos con las intervenciones autorizadas en el período anterior, mientras las demás se limitan simplemente a reproducir dichas razones. 
Por su parte, la prórroga de la orden dictada por el juzgado de Málaga se autorizó por simple providencia. Ni tampoco se apoya el razonamiento de esa primera solicitud en el contenido concreto de las conversaciones intervenidas, de las que no se entrega al juez transcripción alguna que pudiera servir como fundamento objetivo a la solicitud. En este caso como en los demás, las órdenes judiciales se limi$\tan$ a asumir las razones aducidas por la Guardia Civil en su solicitud correspondiente, sin examinar su objetividad ni exigir dato alguno para contrastarla (FFJ 9. y $11{ }^{\circ}$ ). Todo lo anterior conduce al Tribunal a apreciar la violación del derecho al secreto de las comunicaciones de los recurrentes. Es más, la insuficiencia del seguimiento judicial de dichas intervenciones y las deficiencias de la introducción en el juicio de sus resultados constituyen, según el Tribunal, una violación adicional de su derecho a un proceso con todas las garantías reconocido en el artículo 24.2 CE: Pues el órgano judicial no sólo no obtuvo ni solicitó los resultados de las grabaciones realizadas en períodos anteriores antes de autorizar la prórroga de las intervenciones. Tampoco obtuvo ni solicitó las cintas originales de dichas grabaciones para su valoración previa a la apertura del juicio oral y finalmente en el desarrollo del propio juicio, sino que se contentó con una síntesis de las conversaciones controladas elaborada por la Guardia Civil, quien también realizó su transcripción. Como tampoco se encargó a un traductor jurado la traducción de los pasajes en italiano y árabe contenidos en esas cintas, ni se permitió en todo caso a la persona interesada escuchar sus contenidos y ratificar la autenticidad de su transcripción $\left(\mathrm{FJ} \mathrm{13} .^{\circ}\right)^{30}$.

Violación, pues, de los derechos al secreto de las comunicaciones y a un proceso con todas las garantías, reconocidos en los artículos 18.3 y 24.2 de la Constitución. El Tribunal debe entrar ahora a analizar sus consecuencias. Debe resolver, en concreto, si la admisión a juicio de la prueba obtenida como resultado de dicha violación constituye, tal y como lo entiende el Tribunal, una violación ex novo del derecho a un proceso con todas las garantías, y si ésta ha desembocado también en una violación de la presunción de inocencia de los recurrentes por su condena en ausencia de prueba legítima. En este punto parece aconsejable interrumpir el hilo narrativo para introducir una serie de reflexiones de alcance más general, relativas tanto a la concepción de la figura de la exclusión de la prueba como a su asunción en nuestro derecho por el Tribunal Constitucional.

3. LA EXCLUSIÓN DE LA PRUEBA INCONSTITUCIONAL. NOTAS TEÓRICAS Y VALORACIÓN DE NUESTRA JURISPRUDENCIA

Ya en otro lugar he tenido ocasión de comentar con detalle los orígenes en la jurisprudencia estadounidense de lo que se conoce como "regla de la exclusión" (exclusionary rule), orígenes que se remontan a finales del siglo pasado y al contexto de la protección del derecho de propiedad en el seno de la Cuarta Enmienda,

30. Sobre la obligación judicial de seguimiento de las intervenciones ordenadas, consúltese B. RodríGuez Ruzz, El secreto de las comunicaciones ..., cit. págs. 99 y ss. 
así como el sentido que dicha figura tiene hoy en el marco del derecho a la intimi-

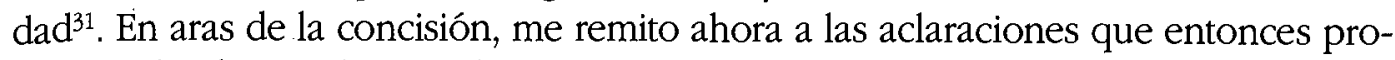
porcionaba, limitándome a destacar a continuación las notas más relevantes de cara a los propósitos de este comentario. Quisiera comenzar insistiendo en la idea de que la tutela de un derecho fundamental forma parte del contenido conceptual de dicho derecho, que sin ella nos movemos en el terreno no de los derechos, sino de las promesas o de los programas políticos, y que es función de jueces y tribunales garantizar esa tutela en cada caso concreto. Función cuyo desempeño nuestra Constitución ha convertido, además, en objeto de un derecho fundamental independiente (artículo 24). Ello se traduce en el deber de jueces y tribunales de intentar que todo titular de un derecho se vea afectado en su disfrute en la menor medida posible. Lo cual implica la obligación tanto de prevenir en lo posible su violación ${ }^{32}$, como de poner fin a violaciones ya iniciadas pero no terminadas, las llamadas violaciones continuas, así como en último extremo de minimizar las consecuencias de las que pueden considerarse irremediablemente completas. Entre éstas últimas se encuentran, por ejemplo, las del derecho a la intimidad, ya que toda injerencia en él ocasiona una pérdida de intimidad inmediata y definitiva, imposible de restablecer. Las violaciones del derecho a la propiedad son, por el contrario, continuas, en el sentido de que se prolongan en el tiempo mientras el titular del derecho se vea privado de lo que legítimamente le corresponde. Pues bien, en los Estados Unidos, el derecho contra registros y embargos irrazonables reconocido en la Cuarta Enmienda fue interpretado hasta mediados de este siglo como un derecho instrumental de la propiedad. Mientras así era, la prohibición de utilizar en juicio la prueba obtenida como resultado de una violación de dicha Enmienda se justificó con relativa facilidad sobre la base de la obligación judicial de poner fin a violaciones continuas, en este caso de poner fin a la apropiación ilegítima de propiedad privada mediante su restitución a su titular. Los problemas surgen cuando empieza a entenderse que la Cuarta Enmienda está al servicio del derecho a la intimidad, y ello habida cuenta de la imposibilidad de restituir a los titulares de este derecho en su ejercicio. De ahí las dificultades de la Corte Suprema para justificar la regla de la exclusión en este nuevo contexto, y su tendencia a considerarla, no como un remedio contra la violación de la intimidad, sino como un modo de prevenir, desincentivándolas, posibles violaciones futuras. Lo cual ha terminado por someter la regla de la exclusión a consideraciones de oportunidad político-jurídica, las cuales suelen conducir a una valoración negativa de la conveniencia de aplicarla ${ }^{33}$.

Lo que los tribunales americanos no se han planteado es su obligación de minimizar los efectos de la violación de la intimidad, de reponer a su titular en una situación lo más cercana posible a la del pleno disfrute del derecho, impidiendo la difusión de los datos obtenidos mediante la misma y, por tanto, su utilización en

31. El secreto de las comunicaciones..., cit. págs. 138 y ss.

32. Un ejemplo es la STC 37/1989, de 15 de febrero, en que el Tribunal Constitucional admitió un recurso de amparo contra una providencia judicial que la demandante consideraba lesiva de su intimidad, aunque aún no había surtido efectos sobre ella.

33. Sobre todo ello, El secreto de las comunicaciones..., cit. págs. 142 y ss. 
juicio. Una carencia que es por lo demás coherente con la visión del derecho a la intimidad como un derecho de corte individualista y antidemocrático imperante en Estados Unidos y desarrollado precisamente, y como ya se mencionó, en el contexto de la Cuarta Enmienda. Puede incluso argumentarse que, en la medida en que la intimidad se concibe en términos de autodeterminación informativa, como el control sobre la publicidad que en supuestos concretos haya de otorgarse a datos que nos conciernen, toda difusión de dichos datos equivale a una violación ex novo de la intimidad, en la medida en que los expone ante un público nuevo por encima de nuestra capacidad de control; que impedir por tanto su difusión equivale a prevenir violaciones futuras del derecho a la intimidad ${ }^{34}$. Hablemos en términos de prevenir violaciones futuras o de minimizar los efectos de violaciones pasadas, lo que está claro es que la obligación del poder judicial de tutelar el derecho a la intimidad ha de conducirle a excluir en juicio la prueba obtenida mediante su violación. Obligación ésta que está implícita, ante todo, y como al principio se argumentaba, en el reconocimiento de ese derecho, además de venir exigida por el derecho a la tutela judicial efectiva en su disfrute donde éste sea objeto, como en nuestra Constitución, de reconocimiento independiente.

No ha seguido nuestro Tribunal Constitucional la lógica argumental aquí propuesta en su jurisprudencia sobre el tema. Antes bien, al enfrentarse ya por primera vez a la regla de la exclusión, en la STC 114/1984, de 29 de noviembre, el Tribunal traza en este punto una línea divisoria insuperable entre la violación extraprocesal de los derechos y la actuación en un proceso de jueces y tribunales, negando que el objeto de los primeros llegue a abarcar ala exigencia, con alcance de derecho subjetivo, de no reconocer eficacia jurídica a las consecuencias de cualquier acto atentatorio de tales derechos" (FJ 2. ${ }^{\circ}$ ). Descarta en concreto el Tribunal que la exclusión de la prueba obtenida con violación del derecho al secreto de las comunicaciones venga impuesta por el artículo 18.3, salvo quizás en términos de oportunidad como medida disuasoria de violaciones futuras. Como tampoco parece considerar que se derive del derecho a la tutela judicial efectiva en el disfrute de aquel derecho. Sí entiende que se desprende, por otro lado, del derecho a un proceso con todas sus garantías (artículo 24) así como del derecho a la igualdad procesal de las partes (artículo 14). Lo cual en principio se justifica también en términos de oportunidad, sobre la base de una ponderación en cada caso entre el interés en procurar la verdad en un proceso y el que existe en garantizar a todos el disfrute de sus derechos. Cuando se trata de derechos fundamentales, con todo, el Tribunal sostiene en términos aparentemente incondicionales «la exigencia prioritaria de atender a su plena efectividad, relegando a un segundo término los intereses públicos ligados a la fase probatoria del proceso" (FJ 4. ${ }^{\circ}$ ). Exclusión pues de la prueba inconstitucional. Exclusión que por lo demás abarca a toda prueba posterior que de ella se derive, aunque en sí misma hubiera estado legítimamente practicada, y siempre que exista una "conexión causal entre

34. William C. HefFerman, "On Justifying Fourth Amendment Exclusion", (1989) Wis. L. Rev. pág. 1193, 1201-1202. 
ambos resultados probatorios ${ }^{35}$. Es lo que en los Estados Unidos se conoce como la "doctrina del fruto del árbol envenenado" (fruit of the poisonous tree doctrine ${ }^{36}$ ). Dicha conexión causal puede, con todo, llegar a interrumpirse. Nuestro Tribunal Constitucional ha entendido que este efecto se produce por la confesión del acusado, aunque ésta estuviera en última instancia condicionada por la prueba inconstitucional $^{13}$. Lo mismo debe entenderse que sucede si la misma prueba es obtenida de forma independiente y legítima, así como, según admite el Tribunal, ante la certeza de que, dadas las circunstancias, la prueba hubiera sido en cualquier caso obtenida de forma legítima e independiente ${ }^{38}$.

Fueron precisamente los términos incondicionales de la defensa de la regla de la exclusión por el Tribunal Constitucional los que anteriormente me llevaron a mitigar mi crítica a su separación en este punto entre lo extraprocesal y lo procesal, entre la violación extraprocesal del artículo 18.3 y la exclusión en juicio de la prueba obtenida mediante la misma, así como a la justificación de ésta última con base en argumentos de oportunidad y como resultado de una ponderación ${ }^{39}$. En principio, la reducción de la aplicación de la regla de la exclusión a consideraciones de oportunidad se presenta como resultado de las reticencias a proteger consecuentemente el derecho a la intimidad en contextos donde éste parece colocarse ante todo al servicio de intereses ilegales. Parece pues derivar de la visión individualista de la intimidad que suele imponerse en tales contextos, del olvido, o al menos de una relegación a segundo plano, del papel que a la misma corresponde desempeñar en términos democráticos y de participación. Con todo, la contundencia con que el Tribunal Constitucional consideró la protección del derecho a la intimidad una "exigencia prioritaria" frente a intereses públicos, la extensión incluso de la regla de la exclusión a la prueba derivada de la directamente obtenida en violación de dicho derecho, todo ello permitía contemplar la justificación ofrecida por el Tribunal más como una incoherencia teórica que como una toma de posición consciente contra la función participativa de la intimidad y la tutela consecuente de la misma. A la vista del desarrollo jurisprudencial posterior del tema, sin embargo, y con independencia de que los fundamentos en que se apoya el Tribunal puedan en ocasiones conducir a resultados idénticos a los que más arriba se razonaron, sí me parece necesario insistir ahora en estos últimos. Pues dicho desarrollo pone en evidencia la maleabilidad de los argumentos de oportunidad del Tribunal y la facilidad con que sobre su base la incondicionalidad de la regla de la exclusión puede ser sometida a revisión.

Tomemos la STC 81/1998, de 2 de abril, en que el Pleno del Tribunal Constitucional se enfrenta a una demanda de amparo motivada por la condena en juicio del demandante sobre la base de pruebas (ocupación de droga y testifical de

35. STC $86 / 1995$, de 6 de junio, FJ 3.

36. Nardone v. US, 308 US 338, 341 (1939).

37. STC 86/1995, de 6 de junio, FJ $4 .^{\circ}$

38. STC 81/1998, de 2 de abril. Es lo que se la Corte Suprema de los Estados Unidos ha llamado la excepción del descubrimiento inevitable (inevitable discovery exception) a la regla de la exclusión: Williams v. Brewer, 430 US 387, 407 (1977); Nix $v$. Williams, 467 US 431 (1984).

39. El secreto de las comunicaciones..., cit. pág. 150. 
los guardias civiles que la llevaron a cabo) obtenidas como consecuencia de otras (intervenciones telefónicas) previamente declaradas inconstitucionales por el Tribunal Supremo, y que el Tribunal Constitucional no ha de volver a examinar. El Tribunal se apoya aquí en dos tipos de consideraciones para apreciar la constitucionalidad de la utilización en juicio de la prueba derivada, de las cuales, y pese a la confusá fraseología empleada, sólo una está dedicada a determinar su constitucionalidad, mientras que la otra determina más bien las condiciones de su exclusión como una circunstancia independiente de la anterior. La primera consideración es, en efecto, de tipo interno, y hace depender la constitucionalidad de la prueba derivada de la inexistencia de un nexo causal entre ella y la originaria, o de la ruptura de ese nexo. En relación con éste el Tribunal Constitucional acepta como razonable la argumentación del Tribunal Supremo, que entiende dicho nexo como interrumpido sobre la base de que, habida cuenta del estado de la investigación policial, la prueba controvertida hubiera sido obtenida en cualquier caso de forma legítima e independiente (FJ 5. ${ }^{\circ}$. La segunda consideración, de tipo externo, condiciona la exclusión de la prueba derivada a "las necesidades de tutela que la realidad y efectividad del derecho al secreto de las comunicaciones exige" (FJ $4 .^{\circ}$ ). Y es aquí donde reside el problema. Pues con ella el Tribunal introduce de nuevo argumentos de oportunidad político-jurídica donde se suponía que éstos ya habían determinado la exclusión incondicional de la prueba obtenida con violación de un derecho fundamental. Y lo hace, además, en términos preventivos que recuerdan a los que predominan en los Estados Unidos y que atienden al efecto disuasorio de la exclusión de la prueba respecto de violaciones futuras, por encima pues de su papel como garante del disfrute de los derechos. En este sentido el Tribunal valora la intencionalidad de la violación originaria por parte del juez, así como la importancia objetiva de dicha violación y su relación con la gravedad del delito que estaba siendo investigado. En el presente caso, la inconstitucionalidad de la prueba originaria se debía a deficiencias en la expresión judicial del presupuesto legitimador de la intervención de comunicaciones, en concreto a la falta de expresión de datos objetivos que justificaran dicha intervención y que fueran más allá de las simples sospechas a que se refiere la solicitud policial. A la vista de ello, la violación del derecho se atribuye más a un error en la actuación judicial que a negligencia o intencionalidad. En tales circunstancias, el Tribunal atribuye a la exclusión de la prueba un mínimo efecto disuasorio de violaciones futuras, efecto éste que se considera en todo caso satisfecho con la declaración de inconstitucionalidad y consiguiente exclusión de la prueba originaria por el Tribunal Supremo, y no tiene porqué perseguirse pues además con la exclusión de la prueba derivada (FJ $6 .^{\circ}$ ).

Y es cierto que en la STC 81/1998 el Tribunal sólo aprueba la utilización de la prueba derivada si la misma aparece justificada tanto desde el punto de vista interno como externo, con lo que las razones de oportunidad recién expuestas deben en principio sumarse a la ausencia de nexo causal con la prueba inconstitucional original, no pueden imponerse por encima de la existencia de éste. Una vez articuladas, sin embargo, dichas razones corren el peligro de adquirir vida propia y desvincularse del marco analítico en el que fueron introducidas, sobre todo 
al ser aplicadas a la exclusión de prueba originaria. Buen testimonio de ello es el voto particular de Cruz Villalón a la STC 49/1999, en que las "necesidades esenciales de tutela del derecho" y el "efecto disuasorio" son llamados a ocupar un papel central en el análisis de la exclusión de la prueba directamente inconstitucional. La cual se hace depender de forma directa e independiente de ese tipo de consideraciones de oportunidad, hasta el punto de afirmarse que ala vulneración de un derecho sustantivo [no tiene por qué] exigir la consecuencia de la anulación de la condena, a partir de las necesidades esenciales de tutela del derecho fundamental al secreto de las comunicaciones".

Bien distinto es, con todo, el tono de la mayoría en la STC 49/1999 que provocó precisamente el citado voto particular. En lo que a las pruebas originarias en este caso se refiere, las cintas grabadas y sus transcripciones, la sentencia se atiene estrictamente al análisis de la regla de la exclusión introducido en la STC 114/1984 arriba comentada, que la defiende sobre la base del derecho a un proceso con todas las garantías en términos aparentemente incondicionales. Declara por tanto la inconstitucionalidad de la admisión como prueba en juicio del contenido de las conversaciones intervenidas. De ello se deriva también la violación de la presunción de inocencia de quienes fueron condenados exclusivamente sobre la base de las mismas. En cuanto a las pruebas que de ella se derivan, la aprensión de los participantes en el desembarco de droga y el testimonio policial al respecto, el Tribunal sí asume el planteamiento de la STC 81/1998, las consideraciones de tipo interno y externo que alli se introdujeron como condicionantes de su utilización en juicio. Sin embargo, y una vez establecidos éstos como criterios de valoración de la constitucionalidad de la prueba derivada, el Tribunal afirma, citando la STC 81/1998, que la aplicación de los mismos corresponde en principio a los tribunales ordinarios. Razón por la cual decide retrotraer las actuaciones al momento anterior a la proposición de prueba, para que excluidas las directamente inconstitucionales puedan los tribunales ordinarios determinar si las demás traen o no causa directa de ellas, si son pues lícitas o están también sujetas a exclusión.

Nos encontramos, en fin, tanto en el tratamiento de la exclusión de las pruebas originarias como de las derivadas, ante nuevas manifestaciones del tono de precaución que domina la STC 49/1999. El cual ha conducido aquí a resultados que deben ser parcialmente objeto de crítica. Pues si bien la conclusión del Tribunal en relación con las pruebas originarias, a pesar de las carencias teóricas de su razonamiento, merece valoración positiva, los resultados a que llega en lo que a las derivadas concierne se presentan en parte como insuficientes, en parte como excesivos. Pues por un lado, la sentencia no se distancia de las consideraciones realizadas en la STC 81/1998 en torno a las necesidades de tutela del derecho, sino que las asume como argumentos de oportunidad jurídico-política de cara a la aplicación de la regla de la exclusión. Por otro lado, y como señalan los Magistrados D. Julio Diego González Campos y D. Pablo García Manzano en su voto particular, el Tribunal bien pudo valorar la constitucionalidad de la prueba derivada sobre la base de los criterios que él mismo proporciona y de los datos que del caso posee. Y siendo su valoración posible, en el caso presente era también aconsejable; habida cuenta de las dificultades de una retroacción de actuaciones tras el 
tiempo transcurrido, y del gravamen que para los recurrentes supone su sometimiento como acusados a un nuevo proceso penal. Parecería que el Tribunal hubiera querido evitar tanto el repudio de su propia doctrina, por lo demás tan reciente, sobre las condiciones de constitucionalidad de la prueba derivada, como los riesgos de asumir su aplicación, de decidir que sobre su base las pruebas derivadas en el presente caso no están viciadas de inconstitucionalidad. En verdad esta solución podía haber parecido la de justificación más probable desde el punto de vista externo, sobre la base de argumentos idénticos a los utilizados en la STC 81/1998, pero no resultaba en absoluto tan inmediata desde el punto de vista interno. Más bien la conexión casual entre las pruebas originarias y las derivadas se presenta como la línea de argumentación más evidente. En favor de su ruptura sólo cabe imaginar el nada convincente argumento de que la aprensión in situ de los participantes en el delito investigado es un hecho suficientemente significativo como para romper dicho nexo. Y si la retroacción de actuaciones es merecedora de crítica en relación con la valoración de la prueba derivada, mucho más criticable es que haya sido también ordenada en relación con quienes fueron condenados exclusivamente sobre la base de pruebas originarias declaradas inconstitucionales, donde el tono de cautela carece de justificación alguna y parece asumirse casi por inercia.

\section{REFLEXIONES SOBRE LA EVOLUCIÓN DE LA CONSTITUCIÓN Y LAS "CARENCIAS PRETÉRITAS" DE CONSTITUCIONALIDAD}

Hasta aquí las consideraciones relativas a la regla de la exclusión. Con ellas se ha pretendido sentar los presupuestos teóricos de su aplicación incondicional en casos de violación de derechos fundamentales, razonando en concreto en el contexto del derecho a la intimidad y al secreto de las comunicaciones, al subrayar que su aplicación es parte de la obligación de jueces y tribunales de tutelar el disfrute de dichos derechos. Ello convierte a la regla de la exclusión en inmune frente a todo tipo de consideraciones en torno a las "necesidades de tutela" de los derechos. Cuestión distinta, y que aún debe ser explorada, es hasta qué punto dichas necesidades pueden llegar a condicionar la propia noción de violación de un derecho, los supuestos en que una injerencia en su ejercicio debe considerarse inconstitucional, y la prueba obtenida sobre su base ser excluida en juicio. Más concretamente, la cuestión que aún queda por resolver es si decisiones judiciales pueden adolecer, como señala Cruz Villalón, de "Carencias pretéritas" de constitucionalidad, si los requisitos de constitucionalidad de las injerencias en un derecho elaborados por el Tribunal Constitucional (en este caso la obligación de mencionar explícitamente las razones objetivas que justifican una intervención telefónica) deben imponerse o no con efectos retroactivos, a decisiones judiciales dictadas con anterioridad a su elaboración, la cual tuvo lugar en este caso en la propia sentencia que exige su cumplimiento.

A primera vista, la cuestión de fondo parece reducirse a la siguiente alternativa: o bien dichos requisitos se encuentran implícitos en la Constitución, abiertos 
tan sólo a interpretación deductiva y de carácter meramente declaratorio, por lo que tienen carácter original y se imponen con efectos retroactivos; o bien su imposición por el Tribunal Constitucional tiene carácter constitutivo. Pero esto último equivale a convertirlos en derecho creado por el propio Tribunal, lo cual, y por encima de la difícil cabida que dicho derecho tiene en nuestro esquema de separación de poderes, priva a los mencionados requisitos de su rango constitucional. Tal disyuntiva se encuadra en una concepción de la Constitución y de los derechos fundamentales de inspiración iusnaturalista, como normas jurídicas cuyo contenido normativo se encuentra prefijado de forma intemporal y definitiva, un contenido normativo que sólo cabe por tanto descubrir e interpretar. La cuestión anterior encierra, sin embargo, matices más complejos si se asume que más que una estructura estática, la Constitución y el ordenamiento jurídico son una realidad dinámica. Los cuales están sujetos, más que a interpretación declarativa, por un lado, y suplemento constitutivo, por otro, a una labor de concreción ${ }^{40}$. Para presentar esta imagen de la Constitución me apoyaré, como punto de partida, en la distinción elaborada por Klaus Günther entre argumentos de justificación y de aplicación de normas jurídicas ${ }^{41}$, entre el argumento de que existen suficientes razones para adoptar una norma, y el argumento de que esa norma es la más adecuada para la regulación de un caso concreto. Una distinción que Günther sitúa en el contexto de la teoría del discurso. Estos dos momentos, la justificación y la aplicación, informan la imparcialidad de las normas, y con ella su corrección en términos discursivos. La cual dependerá de que todos los participantes en el discurso de su justificación acepten las consecuencias de su adopción en el marco de las circunstancias previstas por ella (principio de universabilidad), y de que el discurso de aplicación seleccione la norma más adecuada para la resolución de un caso una vez consideradas todas las circunstancias de éste. En concreto, los discursos de aplicación deben tener en cuenta todas las normas que integran un sistema normativo y confrontarlas con las características del caso. La decisión sobre qué norma es la más adecuada para su solución será el resultado de una labor de concreción de las normas en juego, cuyo punto de referencia es la coherencia del sistema normativo: se tratará de aquélla cuya aplicación mejor respete la armonía entre todas las demás que son en principio aplicables, teniendo en cuenta las posibilidades semánticas de dichas normas y las distintas lecturas que el supuesto fáctico encierra ${ }^{42}$.

Esta distinción entre discursos de justificación y de aplicación es la que subyace a la separación entre el poder legislativo y el judicial. Mientras el primero se

40. La noción de concreción aquí utilizada se distancia pues de los usos habituales de dicho término, los cuales responden más bien a la alternativa recién descrita. La concreción de una norma suele entenderse, bien como sinónimo de su interpretación, como un acto pues aclarativo y por tanto puramente declarativo, bien como la elección entre las distintas soluciones que la norma deja abiertas, como un acto que encierra un elemento creativo (cifr. Manuel MEDINA GuERrERo, “Escritos sobre Derechos Fundamentales' de Böckenförde", REDC núm. 41 (1994), págs. 323, 328). La noción aquí propuesta se presenta más bien, como enseguida veremos, como una simbiosis de los polos de dicha alternativa.

41. Der Sinn für Angemessenbeit. Anwendungsdiskurse in Moral und Recht. Suhrkamp, Frankfurt am Main, 1988.

42. Klaus GüNTHER, Der Sinn für Angemessenbeit ..., cit., págs. 287 y ss. 
reserva la adopción de normas sobre la base de discursos de justificación, el segundo asume la aplicación de las ya existentes, o el juicio final sobre la adecuación de su aplicación por otros operadores jurídicos. También la labor del Tribunal Constitucional refleja estos dos momentos. Así el control de constitucionalidad de las leyes se apoya en discursos de justificación que responden a los que el legislativo desarrolló para su elaboración, desde la perspectiva esta vez de un análisis de su constitucionalidad. De ahí que el Tribunal Constitucional haya sido concebido como el alter ego del legislador encargado de controlar sus discursos de justificación desde el punto de vista de sus límites constitucionales, y el control de constitucionalidad de las leyes como la "continuación del proceso legislativo por otros medios y bajo circunstancias diferentes" ${ }^{43}$. Del mismo modo, la protección de derechos fundamentales se basa en discursos que responden, desde el punto de vista de su constitucionalidad, a los que se alega han provocado su violación, sean éstos discursos de aplicación de normas o, en los supuestos de violación de derechos por normas jurídicas, discursos de justificación.

Pues bien, como arriba indicaba, los discursos de aplicación concretan el marco normativo existente al aplicarlo a un supuesto específico. Al hacerlo, con todo, al proponer la solución de un caso concreto, estos discursos deben también incorporar un elemento justificativo, en el sentido de que deben razonar la validez de dicha solución en el marco de las circunstancias del caso consideradas sobre la base del principio de universabilidad. El cual requiere que dicha solución sea justificada como aplicable a todos los supuestos en que concurran esas mismas circunstancias $^{44}$. Ello explica la figura del precedente, el que la solución de un caso constituya un ejemplo a seguir en la de otros posteriores, el que la misma se sume pues al espectro normativo a tener en cuenta en futuros discursos de aplicación. Por su parte, los discursos de justificación de las normas deben desarrollarse dentro del marco del principio de jerarquía normativa, en última instancia dentro del marco constitucional. Así, y además de justificar la normas elaboradas, también concretan las posibilidades abiertas por marcos normativos superiores, en atención a las circunstancias más o menos abstractas a que la norma que ahora se justifica tendrá a su vez que aplicarse.

De todo lo anterior se deduce una imagen dinámica del ordenamiento jurídico y, en lo que aquí interesa, de la Constitución, en el sentido de que ésta no contiene una formulación apriorística del espectro normativo que puede desarrollarse dentro de su marco. Antes bien, las posibilidades que dicho marco abre deben ser concretadas, tanto a nivel legislativo como a nivel de la aplicación judicial de la ley y de la Constitución, para adaptarlas a los supuestos fácticos que son objeto tanto de regulación abstracta como de solución en casos concretos. De ahí que nuevas circunstancias en el mundo de los hechos, o una nueva apreciación de dichas circunstancias, puedan imponer desde el punto de vista constitucional la necesidad

43. Jürgen Habermas, Faktizität und Geltung, Suhrkamp, Frankfurt am Main, 1994, pág. 319; Andrăs SAÍ, "Constitucional Adjudication in Light of Discourse Theory", Cardozo Law Review vol. 17 (1996), pág. 1193, 1205, 1208.

44. Klaus GïNTHER, Der Sinn für Angemessenheit..., cit. págs. 95, 267. 
de promulgar nuevas normas y/o de desarrollar nuevas líneas jurisprudenciales en la aplicación de las normas existentes, incluidas la propia Constitución y los derechos fundamentales. Y de ahí también que una alteración en la concreción legislativa o jurisprudencial de la Constitución, motivada por las razones anteriores, altere consigo los términos en que se concibe el contenido normativo de ésta, provocando en su caso la inconstitucionalidad de normas y de líneas jurisprudenciales cuya conformidad constitucional hasta entonces no se discutía.

Esta visión evolutiva de la Constitución tiene su reflejo, por ejemplo, en la figura de la inconstitucionalidad sobrevenida asumida por el Tribunal Constitucional Federal alemán. De ahí sus llamadas al legislador a reformar una ley, no sólo en supuestos en que ésta se considera inconstitucional en su origen, sino en otros en que se estima que, con el tiempo, se ha convertido o es previsible que se convierta en contraria a la Constitución. Y ello tanto por contradecir los dictados constitucionales según una nueva concepción de los mismos ${ }^{45}$, como por no satisfacer el nivel de desarrollo legislativo que éstos exigen, habida cuenta ante todo de una evolución de las circunstancias fácticas que son objeto de atención constitucional o de una anterior apreciación errónea de dichas circunstancias ${ }^{46}$. El Tribunal puede incluso requerir del legislador una nueva ley que cubra nuevos supuestos de hecho, por considerar que es su inactividad la que está viciada de inconstitucionalidad sobrevenida. Asimismo el Tribunal Constitucional federal ha seguido con frecuencia la práctica de anunciar los cambios en su propia línea doctrinal, normalmente en forma de obiter dicta, antes de introducirlos de forma definitiva como jurisprudencia vinculante ${ }^{47}$. En esta línea se sitúa igualmente la figura americana de la "derogación prospectiva" (prospective overruling). Dicha figura, introducida en los Estados Unidos por jueces y tribunales ya a mediados de siglo pasa$\mathrm{do}^{48}$, rompe con la tradicional concepción Blackstoniana del common law de que el poder judicial sólo descubre derecho, que la derogación de jurisprudencia anterior equivale al descubrimiento de que, después de todo, es la nueva doctrina la que refleja el verdadero derecho, y tiene como tal que aplicarse retroactivamente ${ }^{49}$. La Corte Suprema ha elaborado desde entonces una rica casuística en torno a la derogación de su propia jurisprudencia, distinguiendo entre situaciones en que la misma ha de ser objeto de aplicación estrictamente prospectiva, no afectando siquiera al caso enjuiciado, otras en que ha de ser de aplicación limitadamente retroactiva, afectando bien sólo al caso enjuiciado, bien a éste y a todos los que están aún pendientes de solución definitiva, y por último otras en que su aplicación debe ser plenamente retroactiva, permitiendo la revisión de casos ya

45. BVerfGE 43, 291, 321; 45, 187, 252; 65, 1, 55 y ss; $68,287,309 ; 71,364,393$; cifr. Klaus STERN, Das Staatsrecht der Bundesrepublik Deutschland, Band III/I, C.H. Beck'sche Verlagsbuchhandlung, München, 1988, Par. 73 IV 4, pág. 1313 y ss.

46. BVerfGE 16, 174, 181 y ss, 187 y ss; $18,315,332$ y ss; $25,1,12$ y ss; $33,171,189 ; 37,104$, $115 ; 43,291,321 ; 49,89,130$; cifr. Klaus Stern, ibidem.

47. BVerfGE 40, 296, 328; 69, 1, 77; 69, 315, 367; 73, 40, 101; cifr. K. STERN, ibidem.

48. Bingham v. Miller, 17 Ohio 445 (1848); Gelpcke v. Dubuque, 1 Wall 175, 17 L ed 520 (1863); cifr. Linkletter v. Walker, 381 U.S. 618, 624 (1965).

49. Cifr. Linkletter $v$. Walker, cit. en 623. 
juzgados $^{50}$. La Corte ha puntualizado, con todo, que la aplicación retroactiva o prospectiva de nuevas doctrinas judiciales no deriva en ningún caso de mandato constitucional alguno, que se trata de una cuestión abierta a consideraciones de oportunidad que deben ser valoradas por los propios jueces y que se concentran principalmente en las consecuencias de la retroactividad de la nueva doctrina ${ }^{51}$. Así, el nivel de retroactividad de ésta se decide sobre la base de criterios que tienen en cuenta, sobre todo, la finalidad de su introducción y el grado en que la misma venía ya o no satisfecha en el pasado por otros medios, los efectos de su retroactividad en el desarrollo ordinario de la administración de justicia, y el grado en que los tribunales se han adherido de buena fe a la doctrina antigua en el caso concreto $^{52}$. Desde la perspectiva de la visión evolutiva de la Constitución arriba postulada, sin embargo, parecería más adecuado enjuiciar la retroactividad de una nueva doctrina en atención a sus raíces constitucionales, a si su introducción es el resultado de una nueva línea de comprensión de la Constitución, o si se trata más bien de un requisito constitucional irrenunciable, cuya falta de observancia en el pasado debe entenderse como un error de interpretación.

Ahora bien, dentro de esta última posibilidad entran también algunos supuestos de evolución jurisprudencial, supuestos más sutiles y más comunes que los arriba referidos y que reflejan el carácter progresivo con que se desarrollan las líneas de concreción de la Constitución. Se trata, en definitiva, de momentos precisos dentro de los procesos de perfeccionamiento o matización de la jurisprudencia relativa a la interpretación de un precepto constitucional determinado. Matización de su interpretación que ciertamente enriquece la concreción de la Constitución al sentar un precedente para la solución de casos futuros, pero que a diferencia de la derogación de doctrina anterior, no es resultado de un cambio en su comprensión. Más bien puede y suele tratarse de puntualizaciones introducidas al hilo de lo que requieren las circunstancias fácticas de los casos concretos que deben ser objeto de decisión. En este sentido se ha hablado de incrementalismon judicial, de una técnica mediante la cual los órganos judiciales enriquecen

50. Para una revisión de dicha jurisprudencia, consúltese George K. Chamberlin, J.D., "United States Supreme Court's Views as to Retroactive Effect of its own Decisions Announcing New Rules" Annotation, Supreme Court Decisions, 65 L Ed 2d 1219 (1980), actualizada en 1996.

51. Linkletter $v$. Walker, cit. en 629.

52. Stovall v. Denno, 388 U.S. 293, 297 (1967). Además, la concesión de efectos retroactivos sólo al caso enjuiciado se apoya en el interés en "premiar" a las partes que han provocado el cambio de jurisprudencia, en no desincentivar tales iniciativas. Las partes, con todo, siempre pueden argumentar en favor de la retroactividad de la nueva doctrina en términos más generales, o en el sentido de que la nueva doctrina se encontraba ya implícita en alguna anterior (cifr. G. K. ChamberLin, J.D., "United States Supreme Court's Views...", cit., pág. 1226). Por lo demás, la aplicación retroactiva de una nueva doctrina exclusivamente al caso juzgado ha sido criticada por algunos magistrados de la Corte Suprema quienes, creo que acertadamente, consideran una cuestión elemental de justicia que la misma se aplique por igual a todos los casos pendientes de solución, y por tanto bien en términos retroactivos más amplios o bien en términos exclusivamente prospectivos (cifr. ibidem, pág. 1246). Recientemente la Corte parece haber asumido también esta postura, indicando que si una nueva doctrina se aplica al caso en el que fue introducida, dicha doctrina debe considerarse de aplicación retroactiva a todos los casos aún pendientes de solución (Harper v. Virginia Department of Taxation, 509 U.S. 86 (1993); Reynoldsville Carket Co. V. Hyde, 514 U.S. 749 (1995)). 
y puntualizan la jurisprudencia anterior sin llegar a romper con ella ni a introducir en ella elementos especialmente novedosos, sin dejar pues de respetar en principio su adhesión al precedente judicial ${ }^{53}$. Técnica ésta del incrementalismo que parece especialmente ajustada para definir el tratamiento judicial del requisito de la motivación. Pues según se ha observado en el contexto de las decisiones administrativas, la valoración que jueces y tribunales suelen hacer del requisito de la motivación tiende a endurecerse con el tiempo. Así, y aunque en un principio exijan su cumplimiento en términos formales, acaban siempre insistiendo también en su contenido material, un contenido que con el tiempo especifican cada vez más y con cuyo respeto se muestran pues cada vez más exigentes ${ }^{54}$.

Pues bien, a la vista de todas las consideraciones anteriores, y partiendo de la indisolubilidad del vínculo que aquí se ha defendido entre la violación del derecho al secreto de las comunicaciones y la exclusión de la prueba obtenida como resultado de la misma, el caso examinado por la STC 49/1999 suscita las cuestiones siguientes. ¿Son las carencias constitucionales de las órdenes judiciales examinadas el resultado de una jurisprudencia "incrementalista" en torno al artículo 18.3, a la vista de las circunstancias de hecho que en cada caso son motivo de examen; o nos encontramos más bien ante la introducción de nuevas exigencias constitucionales que responden a una alteración en el universo fáctico al que se aplica dicho artículo, e inducida en última instancia a nivel normativo por la sentencia del TEDH en el caso Valenzuela? ¿Deben pues los requisitos de constitucionalidad que en dicha sentencia se exigen aplicarse con efectos retroactivos o tan sólo en términos prospectivos? Aunque argumentando en el contexto de las "necesidades de tutela" y de la aplicación de la regla de la exclusión, y no en el de la existencia de violación del derecho, el voto particular de Cruz Villalón a la STC 49/1999 defiende esta segunda solución. En opinión del Presidente del Tribunal, "no es sino el momento en que diversas Sentencias han ido perfilando el contenido del derecho fundamental ... cuando la consideración de las necesidades de tutela del derecho deben imponer, ex artículo $18.3 \mathrm{CE}$, la prohibición de admisión o valoración de las pruebas". El Tribunal en su mayoría se inclina, por el contrario, por la solución opuesta. En este sentido, ya hạbía defendido el carácter irrenunciable, desde el punto de vista constitucional, de la exigencia de que toda motivación judicial de la intervención de comunicaciones tenga contenido sustantivo ${ }^{55}$. Y lo mismo se afirma ahora en la STC 49/1999 en relación con la exigencia de objetividad de los motivos alegados; pues afirmar lo contrario "supondría dejar el derecho fundamental al secreto de las comunicaciones de todos los ciudadanos al arbitrio de los poderes públicos" (FJ 8..$^{\circ}$.

Es esta última posición la que parece más adecuada a las circunstancias del caso. Pues a pesar de las simpatías que pueda despertar el que la actuación judicial fuera

53. Martin SHAPIRO, "Incrementalism or Stare-Decisis?", (1965) Law in Transition Quarterly, págs. 134 y ss.

54. Martin SHAl'IRO, "The Giving Reasons Requirement", (1992) The University of Cbicago Legal Forum, pág. 179.

55. STC $85 / 1994$, de 14 de marzo, FJ $3 .^{\circ}$ 
anterior a la expresión por el Tribunal Constitucional de las carencias de constitucionalidad que se le imputan, éstas no están sino implícitas en el requisito de que toda intervención de comunicaciones debe apoyarse en una orden judicial. Y es que al igual que no cabe hablar de orden judicial si ésta no está motivada, tampoco hay motivación sin expresión de elementos objetivos que justifiquen la intervención, justificación que implica necesariamente una ponderación de los intereses en conflicto. No nos encontramos, en definitiva, ante un cambio de jurisprudencia, ante un supuesto en que los tribunales de justicia hubieran seguido una determinada línea doctrinal ahora declarada inconstitucional y sustituida por otra, en atención a circunstancias fácticas o normativas novedosas. Tal habría sido el caso, por ejemplo, si los órganos judiciales hubieran seguido las indicaciones de la STC 81/1998 relativas a la constitucionalidad de órdenes judiciales de intervención de comunicaciones cuya motivación simplemente asuma las razones subjetivas aducidas por la policía al solicitarlas. Pues en relación con dicha sentencia sí que puede hablarse de un cambio de línea doctrinal. Las intervenciones telefónicas examinadas son, sin embargo, anteriores a la STC 81/1998. Es más, los criterios de constitucionalidad a que el Tribunal Constitucional las somete se encuentran en perfecta consonancia con su doctrina anterior sobre el derecho al secreto de las comunicaciones, y sobre el requisito de la motivación de las limitaciones de derechos fundamentales en términos más generales. Una doctrina respecto de la que, como ya antes se señalaba, la STC 81/1998 había supuesto una ruptura, y que la STC 49/1999 ahora restablece, enriqueciéndola o incrementándola a la vista de las circunstancias del caso. No hay que olvidar, por último, que de lo que en definitiva se trata en un recurso de amparo es de proteger un derecho fundamental tal y como la Constitución lo define y el Tribunal Constitucional lo interpreta, y no, o no en primera línea, de premiar o castigar al poder judicial por la labor realizada al protegerlo. 